\title{
PENINGKATAN EFEKTIVITAS MANAJEMEN PEMBELAJARAN GURU MELALUI PENGEMBANGAN BUDAYA KERJA DAN KOMITMEN ORGANISASI
}

\author{
Kamaludin $^{1}$, Sri Setyaningsih ${ }^{2}$, Adie E. Yusuf ${ }^{2}$ \\ ${ }^{1}$ Guru SMA Negeri 1 Gunungputri \\ ${ }^{2}$ Program Pascasarjana Universitas Pakuan, \\ Email: pasca@unpak.ac.id
}

\begin{abstract}
Effectiveness of teacher learning management is an important element related to the achievement of educational goals, namely to educate the life of the nation. From the data of $P K G$ results, it can be seen that the teacher's learning management effectivity, especially civil servant high school teachers, is not as expected, which means "das sein" is not like "das sollen". Therefore, the effectiveness of teacher learning management is interesting to study. This study aims to find out how the teacher's learning management effectivity can be improved by examining the correlation between the effectiveness of teacher learning management and other variables. These variables are work culture and organizational commitment. The study was conducted using correlational statistical methods to determine whether the other variables, namely work culture and organizational commitment have a positive correlation with the effectiveness of teacher learning management. Based on these results, then an analysis is carried out using the SITOREM Method to reduce recommendations and determine the order of priority improvements that need to be made. The study was conducted on the civil servant teachers (PNS) in senior public high schools (SMA) in the Eastren Bogor Region of Bogor Regency with a study population of 142 teachers and a sample of 105 teachers. The results showed that there was a positive correlation between work culture and the effectiveness of teacher learning management with the strength of the relationship ryl $=0.278$ and there is a positive correlation between organizational commitment and the effectiveness of teacher learning management which is expressed with a correlation coefficient of ry $2=0.293$. These shows that the teacher's learning management effectivity can be improved through the work culture development and organizational commitment as well as from the components of the teacher's learning management effectivity itself
\end{abstract}

Keywords: Teacher's Learning Management Effectivity, Work Culture, Organizational Commitment..

\begin{abstract}
ABSTRAK
Efektivitas manajemen pembelajaran guru merupakan unsur penting terkait dengan pencapaian tujuan pendidikan, yaitu untuk mencerdaskan kehidupan bangsa. Dari data hasil PKG terlihat bahwa efektivitas manajemen pembelajaran guru, terutama guru PNS SMA Negeri tidak seperti yang diharapkan, yang berarti "das sein" tidak seperti "das sollen". Oleh karena itu, efektivitas manajemen pembelajaran guru ini menarik untuk diteliti. Penelitian ini bertujuan untuk mengetahui bagaimana efektivitas manajemen pembelajaran guru dapat ditingkatkan dengan cara meneliti hubungan antara efektivitas manajemen pembelajaran guru dengan
\end{abstract}


variabel lain. Variabel lain tersebut adalah budaya kerja dan komitmen organisasi. Penelitian dilakukan dengan menggunakan metode statistik korelasional untuk mengetahui apakah variabel lain, yaitu budaya kerja dan komitmen organisasi memiliki hubungan positif dengan efektivitas manajemen pembelajaran guru. Berdasarkan hasil ini, kemudian dilakukan analisis dengan menggunakan Metode Sitorem untuk menurunkan rekomendasi dan menentukan urutan prioritas perbaikan yang perlu dilakukan. Penelitian dilakukan pada Guru PNS di SMA Negeri Se-Wilayah Bogor Timur, Kabupaten Bogor dengan populasi penelitian berjumlah 142 guru dan sampel 105 guru. Hasil penelitian menunjukkan bahwa terdapat hubungan positif antara budaya kerja dan efektivitas manajemen pembelajaran guru dengan kekuatan hubungan ry $_{1}=0,278$ dan terdapat hubungan positif antara komitmen organisasi dengan efektivitas manajemen pembelajaran guru yang dinyatakan dengan koefisien korelasi sebesar $\mathrm{ry}_{2}=0,293$. Ini menunjukkan bahwa efektivitas manajemen pembelajaran guru dapat ditingkatkan melalui pengembangan budaya kerja dan komitmen organisasi serta dari komponen efektivitas manajemen pembelajaran guru itu sendiri

Kata Kunci: Efektivitas Manajemen Pembelajaran Guru, Budaya Kerja, Komitmen Organisasi, Analisis Sitorem.

\section{PENDAHULUAN}

Dalam dunia pendidikan manajemen pembelajaran menduduki peranan yang sangat penting. Karena, pada dasarnya manajemen pembelajaran ialah pengaturan semua kegiatan pembelajaran yang dikategorikan dalam kurikulum inti maupun kurikulum penunjang. Sementara realitas dilapangan, tidak sedikit guru-guru yang masih memiliki kompetensi manajemen pembelajaran rendah, sehingga proses pembelajaran terkesan apa adanya. Adapun yang termasuk dalam kegiatan manajemen pembelajaran adalah, perencanaan, pengorganisasian, penggerakan dan pengawas. Kegiatan perencanaan dan pengorganisasian termanifestasi dalam penyusunan perangkat pembelajaran mulai dari program tahunan, program semester, program mingguan, silabus, RPP, analisis hasil evaluasi, program remedial, program pengayaan dan rencana tindak lanjut.

Dalam pelaksanaan dilapangan, tentu masih banyak ditemukan kekurangan maupun kelemahan, baik itu pemerintah, institusi pendidikan maupun masyarakat serta pihak swasta, sehingga pelayanan pendidikan yang diharapkan sesuai amanat UUD 1945 belum terlaksana dengan baik.

Berdasarkan latar belakang di atas, maka perlu dilakukan penelitian untuk mengkaji efektivitas manajemen pembelajaran guru dengan faktor-faktor yang diduga mempengaruhinya.

\section{Efektivitas Manajemen Pembelajaran}

Efektivitas merupakan suatu keadaan dimana tercapainya suatu tujuan yang ingin diharapkan atau dikehendaki melalui suatu penyelesaian pekerjaan sesuai dengan rencana yang telah ditentukan bersama. Menurut Lipham dan Hoeh (dalam Sutrisno, 1994: 3) melihat efektivitas dari segi pencapaian, seperti yang dikemukakannya "effectiveness relates to the accomplihment of the cooperative purpose, wich is sosial and non personal in chengrater.". Hal ini sesuai dengan pendapat Mardiasmo (dalam Sumenge, 2013: 75), bahwa "efektifitas pada dasarnya berhubungan dengan pencapaian tujuan atau target kebijakan (hasil guna). Efektivitas merupakan suatu hubungan antara keluaran (input) dengan tujuan yang harus dicapai, suatu kegiatan operasional dikatakan efektif apabila proses kegiatan mencapai tujuan akhir kebijakan (spending wisely)." Lindgaard dan Shackel (dalam Rahman et al., 2013: 75), 
"Effectiveness, meaning the results of interaction in terms of speed and errors; Effectiveness is measured in terms of speed and error, refers to levels of user performance."

Manajemen merupakan "rangkaian berbagai kegiatan wajar yang dilakukan seseorang berdasarkan norma-norma yang telah ditetapkan dan dalam pelaksanaannya memiliki hubungan dan saling keterkaitan dengan lainnya" Sudjana (dalam Sutrisno, 2000: 3), hal ini mengandung makna konsep manajemen tidak boleh bertentangan dengan norma-norma yang telah ditetapkan. Menurut Usman (Mutia dkk, 2016: 24), menyebutkan manajemen dalam arti luas adalah adalah "perencanaan, pengorganisasian, pengarahan dan pengendalian sumber daya organisasi untuk mencapai tujuan secara efektif dan efisien". Menurut Daft (Haerana, 2016: 2) manajemen adalah "pencapaian sasaran organisasi dengan cara yang efektif dan efisien melalui pelaksanaan, pengorganisasian, kepemimpinan dan pengendalian sumber daya organisasi".

Menurut Haling (Haerana, 2016: 18), Pembelajaran adalah "suatu proses dimana lingkungan seseorang secara sengaja dikelola untuk memungkinkan terjadinya belajar pada diri pebelajar." Sependapat dengan Haling, Mulyana (Haerana, 2016: 18), Pembelajaran pada hakikatnya adalah "...proses interaksi antar peserta didik dengan lingkungannya, sehingga terjadi perubahan perilaku ke arah yang lebih baik...". Menurut Degeng dan Miarso (Haerana, 2016: 18), "pembelajaran menaruh perhatian pada bagaimana membelajarkan pembelajar dan lebih menekankan pada cara untuk mencapai tujuan." Berdasarkan pengertian tersebut, pembelajaran mengandung makna bahwa proses pembelajaran peserta didik dipengaruhi oleh perubahan lingkungan yang disengaja untuk mencapai tujuan.

Dengan demikian dari berbagai pendapat di atas, dapat disintesiskan bahwa efektivitas manajemen pembelajaran guru adalah upaya guru untuk mengatur dan mengelola proses pembelajaran dengan memanfaatkan berbagai sumber daya guna mencapai pembelajaran secara efektif dan efisien.

\section{Budaya Kerja}

Supriyadi dan Guno (dalam Darodjat, 2015: 31)" budaya kerja adalah suatu falsafah dengan didasari pandangan hidup sebagai nilai-nilai yang menjadi sifat, kebiasaan, dan juga pendorong yang dibudayakan dalam suatu kelompok dan tercermin dalam sikap menjadi perilaku, cita-cita pendapat, pandangan serta tindakan yang terwujud sebagai kerja." Darodjat, $(2015,: 35)$, budaya kerja merupakan "sikap hidup serta cara individu bekerja yang bertumpu pada nilai-nilai yang berlaku umum dan telah menjadi sifat, kebiasaan serta kekuatan pendorong yang memberikan daya positif pada individu, untuk senantiasa berhasil dalam bekerja."

Robbin (dalam Darodjat, 2015: 37), "budaya kerja dimaknai sebagai filosofi dasar yang memberikan arahan bagi kebijakan organisasi dalam pengelolaan karyawan dan sebuah sistem makna bersama dibentuk oleh para warganya yang sekaligus menjadi pembeda dengan organisasi yang satu dengan yang lainnya dan budaya kerja mendorong terciptanya komitmen organisasi dan meningkatkan konsistensi sikap karyawan, yang mana keadaan ini akan menguntungkan sebuah organisasi." Ndraha (Safrizal dkk, 2013: 47) menyatakan budaya kerja merupakan "sikap pegawai terhadap pekerjaan dan perilaku pegawai pada waktu bekerja." Selanjutnya, budaya kerja menurut pendapat Rastogi (Frinaldi, 2014:182) "suatu nilai-nilai budaya kerja yang mampu mengarahkan bagi mereka boleh bekerja secara bermutu dan produktif."

Dengan demikian dari berbagai pendapat di atas, dapat disintesiskan bahwa budaya kerja merupakan filosofi yang didasari sikap terhadap organisasi sehingga dapat bekerja secara bermutu dan produktif untuk menguntungkan organisasi tersebut. 


\section{Komitmen Organisasi}

Allen (Wirmayanis, 2014: 210) komitmen merupakan "sikap pegawai yang menyatakan suatu kekuatan relatif mengenai keterikatan pegawai dengan organisasinya dan melibatkan diri di dalamnya." Sebagai bagian dari suatu organisasi, Blau dan Global (Kurniawan, 2015: 98) mendefinisikan komitmen organisasi sebagai "orientasi seseorang terhadap organisasi dalam arti kesetiaan, identifikasi, dan keterlibatan kepada organisasi dan tujuan-tujuannya." Robbins dan Judge (2008: 101) menyatakan komitmen organisasi "merupakan suatu keadaan dimana seorang karyawan memihak organisasi tertentu serta tujuan-tujuan dan keinginannya untuk mempertahankan keanggotaan dalam organisasi tertentu."

Begitu juga pendapat dari Sopiah (Wahyudi dan Sudibya, 2016: 872) menyatakan bahwa komitmen organisasional (organizational commitment) merupakan "tingkat keyakinan karyawan untuk menerima tujuan organisasi sehingga berkeinginan untuk tetap tinggal dan menjadi bagian dari organisasi tersebut."

Dengan demikian dari berbagai pendapat di atas, dapat disintesiskan bahwa komitmen organisasi merupakan suatu sikap yang ditunjukkan seseorang dengan keterlibatan, loyalitas, keinginan untuk tetap berada dalam organisasi dan tidak bersedia untuk meninggalkan organisasinya dalam upaya mencapai tujuan serta nilai-nilai organisasi.

\section{METODE PENELITIAN}

Penelitian dilakukan dengan menggunakan metode statistik korelasional untuk mengetahui apakah variabel lain, yaitu budaya kerja $\left(\mathrm{X}_{1}\right)$ dan komitmen organisasi $\left(\mathrm{X}_{2}\right)$ memiliki hubungan positif dengan efektivitas manajemen pembelajaran (Y). Penelitian dilakukan pada Guru PNS di SMA Negeri Se-Wilayah Bogor Timur, Kabupaten Bogor dengan populasi penelitian berjumlah 142 guru dan sampel 105 guru.

\section{HASIL PENELITIAN}

\section{Pengujian Persyaratan Analisis}

\section{Uji Normalitas}

Uji normalitas yang pertama adalah uji normalitas gallat baku taksiran untuk sebaran data empris dan teoritis dari persamaan regresi antara budaya kerja $\left(\mathrm{X}_{1}\right)$ dengan efektivitas manajemen pembelajaran guru $(\mathrm{Y})$ yaitu $\left(\mathrm{Y}-\hat{\mathrm{Y}}_{1}\right)$, dimana selisih antara sebaran data empiris $\left(\mathrm{Y}_{1}\right)$ dengan nilai taksiran yang diperoleh berdasarkan persamaan regresi $\hat{\mathrm{Y}}=92,793+0,380 \mathrm{X}_{1}$. Dari hasil perhitungan diperoleh nilai $\mathrm{L}_{\text {hitung }}$ sebesar 0,08 sedangkan nilai $\mathrm{L}_{\text {tabel }}$ sebesar 0,09 dengan taraf signifikansi 0,05 terlihat bahwa $\mathrm{L}_{\text {hitung }}<\mathrm{L}_{\text {tabel }}$ sehingga hipotesis yang diterima adalah $\mathrm{H}_{0}$ yang berarti bahwa sebaran data empris dibanding dengan nilai teoritis dengan persamaan regresi $\hat{Y}=92,793+0,380 X_{1}$ menghasilkan sebaran gallat baku berdistribusi normal.

Uji normalitas yang kedua adalah uji normalitas gallat baku taksiran untuk sebaran data empris dan teoritis dari persamaan regresi antara komitmen organisasi $\left(\mathrm{X}_{2}\right)$ dengan efektivitas manajemen pembelajaran guru $(\mathrm{Y})$ yaitu $\left(\mathrm{Y}-\hat{\mathrm{Y}}_{2}\right)$, dimana selisih antara sebaran data empiris $\left(\mathrm{Y}_{2}\right)$ dengan nilai taksiran yang diperoleh berdasarkan persamaan regresi $\hat{\mathrm{Y}}=91,619+0,389 \mathrm{X}_{2}$. Dari hasil perhitungan diperoleh nilai $\mathrm{L}_{\text {hitung }}$ sebesar 0,07 sedangkan nilai $\mathrm{L}_{\text {tabel }}$ sebesar 0,09 dengan taraf signifikansi 0,05 terlihat bahwa $\mathrm{L}_{\text {hitung }}<\mathrm{L}_{\text {tabel }}$ sehingga hipotesis yang diterima adalah $\mathrm{H}_{0}$ yang berarti bahwa sebaran data empris dibanding dengan nilai teoritis dengan persamaan regresi. 


\section{Uji Homogenitas}

Hasil perhitungan pertama yakni nilai efektivitas manajemen pembelajaran guru berdasarkan budaya kerja menunjukkan bahwa nilai $\chi^{2}$ hitung sebesar 30,393 sedangkan $\chi^{2}$ tabel $(0,05)$ sebesar 44,985 . Terlihat bahwa $\chi^{2}{ }_{\text {hitung }}<\chi^{2}$ tabel yang menyebabakan penerimaan hipotesa nol (Ho) yang berarti bahwa sebaran data variabel efektivitas manajemen pembelajaran guru yang dikelompokan berdasarkan variabel bebas budaya kerja berasal dari populasi yang homogen.

Hasil perhitungan kedua yakni nilai efektivitas manajemen pembelajaran guru berdasarkan komitmen organisasi menunjukkan bahwa nilai $\chi^{2}$ hitung sebesar 37,422 sedangkan $\chi^{2}$ tabel $(0,05)$ sebesar 47,399 terlihat bahwa $\chi^{2}$ hitung $<\chi^{2}$ tabel yang menyebabkan penerimaan hipotesa nol (Ho) yang berarti bahwa sebaran data variabel efektivitas manajemen pembelajaran guru yang dikelompokan berdasarkan variabel bebas komitmen organisasi berasal dari populasi yang homogen.

\section{Pengujian Hipotesis}

1. Hubungan antara budaya kerja $\left(X_{1}\right)$ dengan efektivitas manajemen pembelajaran guru (Y).

Berdasarkan hasil Uji-F pada Tabel 20, diperoleh data $F_{\text {hitung sebesar 8,600 dengan Ftabel }}$ sebesar 3,933. Dikarenakan $F_{\text {hitung }}$ lebih besar dari $F_{\text {tabel, }}$, baik itu dengan taraf signifikansi 0,05 mapun 0,01, maka dapat disimpulkan bahwa koefisien korelasi ry 1 sangat signifikan. Hal ini didukung juga oleh hasil Uji-t diperoleh nilai sebesar 3,056. Karena $t_{\text {hitung }}$ lebih besar dari $t_{\text {tabel, }}$ maka koefiisen korelasi antara budaya kerja dengan efektivitas manajemen pembelajaran guru sangat signifikan. Dengan demikian Hipotesa Ho ditolak dan Hipotesa alternatif diterima.

\section{Hubungan antara komitmen organisasi $\left(\mathrm{X}_{2}\right)$ dengan efektivitas manajemen pembelajaran guru (Y).}

Berdasarkan hasil Uji-F pada Tabel 23, diperoleh data $F_{\text {hitung }}$ sebesar 9,699 dengan $F_{\text {tabel }}$ sebesar 3,933. Dikarenakan $F_{\text {hitung }}$ lebih besar dari $F_{\text {tabel, }}$, baik itu dengan taraf signifikansi 0,05, maka dapat disimpulkan bahwa koefisien korelasi ry2 sangat signifikan. Hal ini didukung juga oleh hasil Uji-t diperoleh nilai sebesar 3,253 Karena thitung lebih besar dari tabel, maka koefiisen korelasi antara komitmen organisasi dengan efektivitas manajemen pembelajaran guru sangat signifikan. Dengan demikian Hipotesa Ho ditolak dan Hipotesa alternatif diterima.

\section{Hubungan antara budaya kerja $\left(X_{1}\right)$ dan komitmen organisasi $\left(X_{2}\right)$ dengan efektivitas manajemen pembelajaran guru (Y).}

Berdasarkan hasil uji $\mathrm{F}$ pada tabel ANAVA, dapat dilihat nilai $F_{\text {hitung }}$ sebesar 4,90 sedangkan $F_{\text {tabel }}$ sebear 3,93 pada taraf signifikansi 0,05 maupun 0,01. Oleh karena itu berdasarkan perhitungan maka $F_{\text {hitung }}$ lebih besar dari $F_{\text {tabel }}$, maka persamaan regresi $\hat{Y}=$ $89,171+0,116 \mathrm{X}_{1}+0,289 \mathrm{X}_{2}$ dapat digunakan untuk memprediksi tingkat efektivitas manajemen pembelajaran guru melalui budaya kerja dan komitmen organisasi. Kekuatan hubungan antara budaya kerja dan komitmen organisasi secara bersama sama dengan efektivitas manajemen pembelajaran guru ditunjukkan oeh koefisien korealsi ry 1,2 sebesar 0,881 dengan koefisien determinasi $\mathrm{r}^{2} \mathrm{y}_{1,2}$ sebesar 0,776 . Hal ini berarti bahwa budaya kerja dan komitmen organisasi secara bersama-sama memberi kontribusi sebesar 77,6\% terhadap efektivitas manajemen pembelajaran guru,

Berdasarkan perhitungan uji-t diperoleh nilai thitung sebesar 35,123 dan nilai tabel dengan taraf signifikansi 0,05 maupun 0,01. Karena $t_{\text {hitung }}$ lebih besar dari $t_{\text {tabel, }}$, maka koefisien korelasi antara budaya kerja dan komitmen organisasi secara bersama sama dengan efektivitas manajemen pembelajaran guru sangat signifikan. 


\section{Uji Korelasi Parsial}

Berdasarkan perhitungan pertama didapatkan thitung sebesar 1,098 antara variabel budaya kerja $\left(\mathrm{X}_{1}\right)$ dengan efektivitas manajemen pembelajaran guru $(\mathrm{Y})$ dimana variabel komitmen organisasi $\left(\mathrm{X}_{2}\right)$ sebagai variabel yang dikendalikan dengan koefisen sebesar 0,107.

Berdasarkan perhitungan kedua didapatkan $t_{\text {hitung }}$ sebesar 0,427 antara variabel komitmen organisasi $\left(\mathrm{X}_{2}\right)$ dengan efektivitas manajemen pembelajaran guru $(\mathrm{Y})$ dimana variabel budaya kerja $\left(\mathrm{X}_{1}\right)$ sebagai variabel yang dikendalikan dengan koefisen sebesar 0,042.

Kesimpulan dari perhitungan tersebut terdapat hubungan positif secara bersama-sama antara budaya kerja $\left(\mathrm{X}_{1}\right)$ dan komitmen organisasi $\left(\mathrm{X}_{2}\right)$ dengan efektivitas manajemen pembelajaran guru $(\mathrm{Y})$. Dimana keberadaan budaya kerja $\left(\mathrm{X}_{1}\right)$ memperkuat hubungan antara komitmen organisasi $\left(\mathrm{X}_{2}\right)$ dengan efektivitas manajemen pembelajaran guru (Y) serta keberadaan komitmen organisasi $\left(\mathrm{X}_{2}\right)$ memperkuat hubungan antara budaya kerja $\left(\mathrm{X}_{1}\right)$ dengan efektivitas manajemen pembelajaran guru (Y).

\section{PEMBAHASAN}

\section{Hubungan positif antara budaya kerja $\left(X_{1}\right)$ dengan efektivitas manajemen pembelajaran guru (Y).}

Berdasarkan hasil uji hipotesis hubungan antara variabel budaya kerja $\left(\mathrm{X}_{1}\right)$ dengan variabel efektivitas manajemen pembelajaran guru (Y) menunjukkan bahwa nilai kekuatan hubungan ry ${ }_{1}$ sebesar 0,278 pada kategori kecil. Sementara nilai determinasi $\mathrm{r}^{2} \mathrm{y}$ sebesar 0,077 , yang berarti budaya kerja memberikan kontribusi dalam peningkatan efektivitas manajemen pembelajaran guru sebesar $7,70 \%$, sedangkan $92,30 \%$ efektivitas manajemen pembelajaran guru dipengaruhi faktor lain. Signifikansi hubungan ini pun diperoleh hasil yang siginifikan pada taraf signifikansi $\alpha=0,05$.

Terdapat hubungan positif antara variabel budaya kerja $\left(\mathrm{X}_{1}\right)$ dengan variabel efektivitas manajemen pembelajaran guru (Y). Hal ini dapat dilihat pada hubungan fungsional variabel budaya kerja $\left(\mathrm{X}_{1}\right)$ dengan variabel efektivitas manajemen pembelajaran guru (Y) yang ditunjukkan dengan persamaan regresi $\hat{Y}=92,793+0,380 X_{1}$, artinya setiap kenaikan satu unit skor variabel budaya kerja dapat meningkatkan skor variabel efektivitas manajemen pembelajaran guru sebesar 0,380 pada konstanta 92,793.

\section{Hubungan positif antara komitmen organisasi $\left(\mathrm{X}_{2}\right)$ dengan efektivitas manajemen pembelajaran guru ( $\mathrm{Y})$.}

Berdasarkan hasil uji hipotesis hubungan antara variabel komitmen organisasi $\left(\mathrm{X}_{2}\right)$ dengan variabel efektivitas manajemen pembelajaran guru (Y) menunjukkan bahwa nilai kekuatan hubungan ry2 sebesar 0,293 pada kategori kecil. Sementara nilai determinasi $r^{2} y$ sebesar 0,086, yang berarti komitmen organisasi memberikan kontribusi dalam peningkatan efektivitas manajemen pembelajaran guru sebesar 8,60\%. sedangkan 91,40\% efektivitas manajemen pembelajaran guru dipengaruhi faktor lain, Signifikansi hubungan ini pun diperoleh hasil yang siginfikan pada taraf signifikansi $\alpha=0,05$.

Terdapat hubungan positif antara variabel komitmen organisasi $\left(\mathrm{X}_{2}\right)$ dengan variabel efektivitas manajemen pembelajaran guru (Y). Hal ini dapat dilihat pada hubungan fungsional komitmen organisasi $\left(\mathrm{X}_{2}\right)$ dengan efektivitas manajemen pembelajaran guru (Y) yang ditunjukkan dengan persamaan regresi $\hat{Y}=91,619+0,389 X_{2}$, artinya setiap kenaikan satu unit skor variabel komitmen organisasi dapat meningkatkan skor variabel efektivitas manajemen pembelajaran guru sebesar 0,389 pada konstanta 91,619. 


\section{Hubungan positif antara budaya kerja $\left(\mathrm{X}_{1}\right)$ dan komitmen organisasi $\left(\mathrm{X}_{2}\right)$ secara bersama-sama dengan efektivitas manajemen pembelajaran guru (Y). \\ Hubungan secara bersama-sama antara variabel budaya kerja dan variabel komitmen} organisasi dengan variabel efektivitas manajemen pembelajaran guru memiliki koefisien korelasi sebesar $r_{\mathrm{y} 1,2}=0,881$ dan koefisien determinasi sebesar $r^{2}{ }_{\mathrm{y} 1,2}=0,776$, sehingga dapat diartikan bahwa 77,6 \% efektivitas manajemen pembelajaran guru dapat dihasilkan melalui variabel budaya kerja dan variabel komitmen organisasi secara bersama-sama, sedangkan $22,4 \%$ efektivitas manajemen pembelajaran guru dipengaruhi faktor lain.

Adapun hubungan fungsional antara budaya kerja dan komitmen organisasi dengan efektivitas manajemen pembelajaran guru dapat digambarkan oleh persamaan $\hat{\mathrm{Y}}$ $=89,171+0,116 \mathrm{X}_{1}+0,289 \mathrm{X}_{2}$

Hal ini berarti variabel efektivitas manajemen pembelajaran guru dapat ditingkatkan oleh variabel budaya kerja dan variabel komitmen organisasi. Setiap peningkatan satu skor variabel budaya kerja dan variabel komitmen organisasi dapat meningkatkan variabel efektivitas manajemen pembelajaran guru $(0,116+0,289)$ pada konstanta 89,171.

Secara parsial variabel budaya kerja lebih dominan dalam meningkatkan variabel efektivitas manajemen pembelajaran guru. Hal ini ditunjukkan oleh uji signifikansi ketika salah satu variabel dikonstankan.

Selain itu untuk melihat seberapa besar kekuatan hubungan antara variabel bebas dan variabel terikat serta untuk mendapatkan solusi optimal dari penelitian ini, dapat dilihat pada gambar konstelasi penelitian dan statistik berdasarkan analisis model Scientific identification theory to conduct operation research in education management (SITOREM). Teori pengenalan ilmiah untuk riset operasi dibidang manajemen pendidikan untuk menentukan penurunan saran atau rekomendasi hasil penelitian (Hardhienata, 2017) seperti yang ditunjukkan pada gambar berikut: 
Efektivitas manajemen

pembelajaran guru (Y)

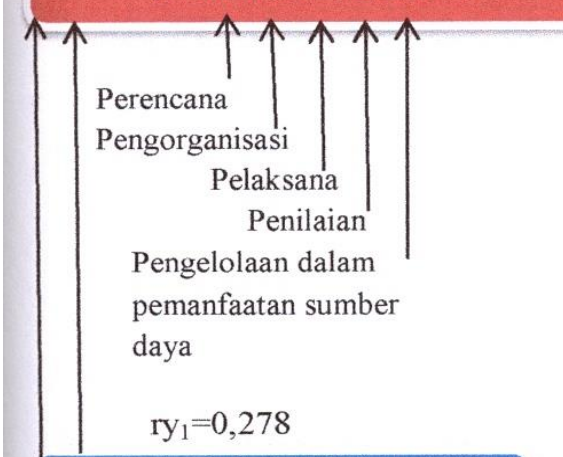

\section{Budaya Kerja $\left(X_{1}\right)$}

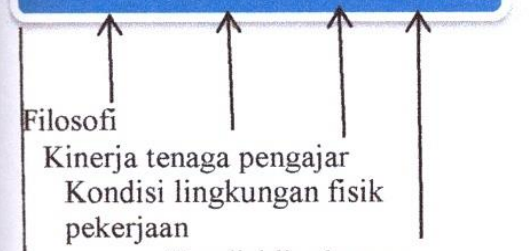

Kondisi lingkungan pekerjaan

$\mathrm{ry}_{2}=0,293$

Komitmen Organisasi $\left(\mathrm{X}_{2}\right)$

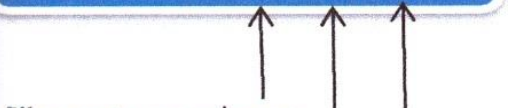

Sikap serta penerimaan terhadap tujuan dan nilai organisasi

Loyalitas, keberpihakan

terhadap organisasi

Keinginan yang kuat

untuk bertahan dalam

organisasi
Bobot dan Nilai Indikator

1. Perencana $(35 \%)(4,1)$

2. Penilaian $(25 \%)(3,2)$

3. Pelaksana $(20 \%)(4,4)$

4. Pengorganisasi $(15 \%)$ $(3,7)$

5. pengelolaan dalam pemanfaatan sumber daya $(5 \%)(3,1)$

Bobot dan Nilai Indikator

1. Kinerja $(40 \%)(4,2)$ tenaga pengajar

2. Kondisi lingkungan fisik pekerjaan $(30 \%)$ $(4,1)$

3. Kondisi lingkungan pekerjaan $(20 \%)(4,6)$

4. Filosofi $(10 \%)(4,5)$

Bobot dan Nilai Indikator

1. Loyalitas, keberpihakan terhadap organisasi $(40 \%)(3,8)$

2. Keinginan yang kuat untuk bertahan dalam organisasi $(35 \%)(3,7)$

3. Sikap serta penerimaan terhadap tujuan dan nilai organisasi $(25 \%)$ $(4,4)$

Gambar 8.

Hasil Analisis Sitorem
Urutan Prioritas Indikator yang perlu dipertahankan

1. Kondisi lingkungan pekerjaan

2. Filosofi

3. Sikap serta penerimaan terhadap tujuan dan nilai organisasi

4. Pelaksana

5. Kinerja tenaga pengajar

6. Perencana

7. Kondisi lingkungan fisik pekerjaan

\section{Urutan Prioritas}

Indikator yang perlu di perbaiki:

1. Loyalitas, keberpihakan terhadap organisasi

2. Keinginan yang kuat untuk bertahan dalam organisasi

3. Pengorganisasi

4. Penilaian

5. Pengelolaan dalam pemanfaatan sumber daya 


\section{SIMPULAN}

Berdasarkan analisis terhadap data hasil penelitian dapat disimpulkan terdapat hubungan positif sangat signifikan antara budaya kerja kepala sekolah dengan efektivitas manajemen pembelajaran guru, antara komitmen organisasi dengan efektivitas manajemen pembelajaran guru, budaya kerja dan komitmen organisasi secara bersama-sama dengan efektivitas manajemen pembelajaran guru. Berdasarkan hasil penelitian ini maka untuk meningkatkan efektivitas manajemen pembelajaran guru dapat dilakukan dengan meningkatkan budaya kerja dan perbaikan pada komitmen organisasi.

\section{DAFTAR PUSTAKA}

Budi Sutrisno. 2010. Hubungan Antara Efektivitas Manajemen Pembelajaran dan Etos Kerja Anggota Musyawarah Guru Mata Pelajaran (MGMP) Dengan Profesionalitas Guru. ejournal.upi.edu. Volume 12 No. 2:1-5.

Hardhienata, S., 2017. The Development of Scientific Identification Theory to Conduct Operation Research in Education Management, IOP Conference Series: Matetials Science and Engineering. Volume 166, 2017, doi: 10.1088/1757-899X/166/I/012017.

Ngunia, Sleegersb, Denessenc, Eddie. 2006. Transformational and Transactional Leadership Effects on Teachers' Job Satisfaction, Organizational Commitment, and Organizational Citizenship Behavior in Primary Schools: The Tanzanian case. School Effectiveness and School Improvement. Volume 17 No. 2: 145-177.

Norlina M. Alia, Rohani Janggaa, Mazlina Ismaila, Siti Nuur-Ila Mat Kamala, and Mohammad Nazri Alib. 2015. Influence Of Leadership Styles In Creating Quality Work Culture Procedia Economics and Finance. hal. 161 - 169.

Nurul Faiqah. 2017. Manajemen Pembelajaran Bahasa Arab di Sekolah (Studi Kasus di SMK Muhammadiyah 2 Palyen Yogyakarta). Jurnal At Tafkir. Volume X No. 1: 64-85.

Suziana Wirmayanis. 2014. Pengaruh Kemampuan Kerja Komitmen Organisasi dan Motivasi Terhadap Kinerja Pegawai (The Effect of Workability, Organizational Commintment and Motivation on Employee Performance). Jurnal Dinamika Manajemen. Volume 2 No. 3: 209-221.

Teguh Triwiyanto. 2015. Manajemen Kurikulum Dan Pembelajaran. Jakarta: Bumi Aksara. Tubagus Achmad Darodjat. 2015. Pentingnya Budaya Kerja Tinggi \& Kuat Absolute. Bandung: Refika Aditama.

Yudi Supriadi. 2014. Penyakit Guru dalam Kurikulum 2013. Kegiatan MGMP Bermutu Dinas Pendidikan Kabupaten Bogor. 